\title{
Research on the Effectiveness of Active Project Driven Teaching Method in Digital Circuit Classroom
}

\author{
Jinfeng $\mathrm{Li}^{1, \mathrm{a}^{*}}$, Wenjie Zhang ${ }^{1, \mathrm{~b}}$ and Renbo $X \mathrm{u}^{1,2, \mathrm{c}}$ \\ ${ }^{1}$ Nanchang Institute of Science and Technology, Nanchang, 330108, China \\ ${ }^{2}$ Physics and Microelectronics Institute, Central South University Changsha 410083 china \\ a524892454@qq.com, b568740355@qq.com, ${ }^{\mathrm{c}} 1310079831 @ q q . c o m$
}

Keywords: Active project driven; Professional quality; CDIO; Independent innovation

\begin{abstract}
Traditional education pays more attention to teaching, and the teacher oriented teaching method is not adapted to the needs of today's society. This paper focuses on the implementation of initiative project driven teaching method which is in line with the society. The active project driven teaching method takes the students as the main body and pays attention to the students' learning, including the cultivation of students' conception, design, implementation and operation ability in the course of study. In order to improve the students' ability of self learning, this paper introduces the active project driven teaching method, to ensure that the students in the learning process, can take the initiative, spontaneous conception, design, implementation and operation of the class project, to ensure efficient classroom efficiency, improve students' ability of independent innovation, and to improve the students' occupation quality. In order to strengthen the docking of schools and businesses, the teaching process driven teaching mode in the project, not only the students should pay attention to the conception, design, implementation and operation ability, but also to strengthen the cultivation of students' moral integrity, and occupation of occupation quality.
\end{abstract}

\section{Introduction}

At this stage, the learning style of college students is mainly passive learning, lack of active learning consciousness. Learning has a passive learning and active points, there is "I want to learn" and "I want to learn". Some people on the surface are also "active" learning, but this "positive" is not voluntary, but external pressure contributed to, is "I want to learn" type. Facts have proved that this kind of learning can neither endure nor seek true knowledge, but it also causes various malpractices, which leads to the decrease of learning efficiency. The study of college students should not be a burden, but it should be a pleasure and a pursuit, and the efficiency of learning will be improved naturally. Active learning is the process of knowing when to learn, to like learning and to be willing to learn. The core of learning is to enjoy learning and have a strong interest in learning. The initiative of learning is not only a hobby of learning, but a connection with personal ideals and goals, determined by psychological stability and tendency, and it is the most direct embodiment of learning enthusiasm.

"Project driven pedagogy" was first developed by American educator Katz and Canadian educator Chad. The view: Knowledge can be constructed and acquired under certain conditions; Learning can improve knowledge, skills, and behavior, attitudes, and values; Education is a conscious, systematic, organized, continuous communication activity. In the early twenty-first Century, Dr. Chad, a Canadian educator, came to Beijing, China, to teach the project driven teaching method". Subsequently, Europe, South America, Oceania, Japan, South Korea also introduced the teaching method. Then Germany enacted the "action oriented project driven teaching method" of the teaching regulations. The specific definition of project driven teaching method refers to the implementation of a complete project by both teachers and students. In the teaching of colleges and universities, the project is to produce a specific and practical value of the products for the purpose. It requires students to use their existing knowledge and experience, through their own hands, to solve practical problems under the guidance of teachers.

In this paper, the active project driven in combination with digital circuit, the digital circuit in the 
real application of active in the course of project driven teaching method, promote the digital circuit of the teaching effect of this course, the project of digital circuit in the course of enterprise and is often used in combination, make students personally on the scene, unity and cooperation, direct contact with the current case, the enterprise can keep pace with the times, learning new knowledge, to complete the project case teaching. In this process, not only improve the performance of students, promote the students' learning effect, strengthen unity and cooperation, can guarantee and social integration, improve the occupation quality, the future can better integrate into society.

\section{Work Program and Practical Significance}

Project driven teaching methods include the following implementation elements: First, there is certain teaching content, practical value of the project; second, the theoretical knowledge and practical skills can be combined; third, it is related to the actual production or business operation of the enterprise; fourth, students can make plans and implement them in groups; fifth, students can use their knowledge to overcome and deal with the problems and failures in the project work; sixth, there is a certain degree of difficulty, the purpose is to enable students to master and use of new knowledge and skills in the process of completion; seventh, we should cultivate the emotion, attitude, values and professional quality; eighth, with fruitful results, teachers and students can evaluate project completion and project effectiveness together.

The practical significance of the project driven teaching method mainly has the following four points.

1. According to the characteristics of human perception, when the stimulus is "listening", memory rate is $20 \%$; when the stimulus is to "see", memory rate is $30 \%$; when the stimulus is "listening + memory", the rate is $50 \%$; when the stimulus is "practice", memory rate is $90 \%$.

2. In the process of building a project, real learning can happen only when one's knowledge does not solve the problems he is facing. Compared with the traditional teaching model, learning is no longer the activity of transferring knowledge by teachers to students, but the process of constructing knowledge by students themselves. Students are not passive acceptance of knowledge, but actively through the existing cognitive structure for processing and construction of the new knowledge, the construction process of the teacher cannot replace, initiative, it is more emphasis on students' social combination, context fusion, teamwork.

3. Xingzhi Tao, a Chinese educationist, once said, "Teaching, learning and doing are one. Teaching, learning and doing is one thing, not three things." Students listen to the teacher to explain the process of learning, learning in the process of operation, which is a learning process, indivisible, research and treatment.

4. Project driven education mode is employment oriented, service for the purpose, to cultivate the moral quality of students' occupation and occupation training objectives, training of technical talents in service line, truly integrated with the society.

At present, most of the students in this school are from the minority areas in the central and western regions. Their learning base is weak and their learning habits are poor, but their thinking is more agile and their practical operation ability is stronger. Therefore, in teaching activities, teachers should train students' thinking, practice, perception and creative ability as much as possible, and constantly sum up and accumulate learning experience in practice; at the same time, teachers aim at individual differences among students, and strive to create a study atmosphere for students.

\section{Primary Coverage}

Project driven teaching method is more suitable for more practical courses, such as the digital circuit research in this paper, students need more hands-on practice ability. The purpose of project driven teaching is to enable students to recognize and improve their theoretical knowledge and skills through a skill's training.

The teacher handed over a relatively independent project to the students themselves. In the course of the process, the students themselves are responsible for collecting information, designing 
programs, implementing projects and evaluation projects. Then students can understand the basic requirements of each link of the project and grasp the whole process. When applying the project teaching method, students' learning process consists of seven steps.

(1) Clear tasks

In this process, teachers need to assign learning tasks, clear learning goals, and help students understand tasks; when students understand the task, they know what they are going to do, what knowledge to learn, what skills to practice and what they will achieve.

(2) Access to information

Students can obtain the relevant information according to the reference materials provided by the teachers or their own access to relevant information, so as to prepare conditions for the smooth start of the project.

(3) Making plans

After the students have clearly defined their tasks, they will work out the work plan in groups and work together.

(4) Make a decision

According to the group's plan, team members put forward various schemes each one airs his own views, and finally by the group discussion, establish the best implementation plan of the project.

(5) Organization and implementation

Students complete their tasks according to the program, and the teachers watch and guide them. Students can always ask questions, and the teacher answers them. Students in the implementation process, students can learn according to their own steps, in the whole process of learning, students can significantly improve learning autonomy, consciousness and learning efficiency.

(6) Process inspection

Students in the process of completing the project, check the work process and results of their own. When problems can't be solved, you can always consult the teacher.

(7) Outcome evaluation

When students complete the project, they display and evaluate the results, and answer other students' questions and communicate with each other. The teacher evaluates the course of the students and the results of the project and corrects the problems that occur during the course of the students' making.

Students can produce a specific product through the implementation of the project. Students see their products, feel the joy of success, students can stimulate the desire to learn, so as to have greater enthusiasm and interest in learning, the next project into the study.

\section{Example Analysis of Project Driven Teaching Method Implementation}

Project name: Designed to implement a 4 bit binary synchronous addition counter.

Content of courses: Counter 74LS161 logic function and its application. Fig. 1 is a 74LS161 commonly used symbol graph. Fig. 2 is the pin diagram (GB symbol).

Experimental equipment: Regulated power supply, digital circuit experiment box, 74LS161.

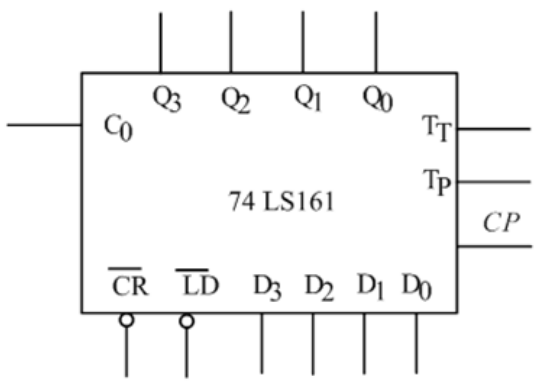

Fig. 1 Common symbol graphics

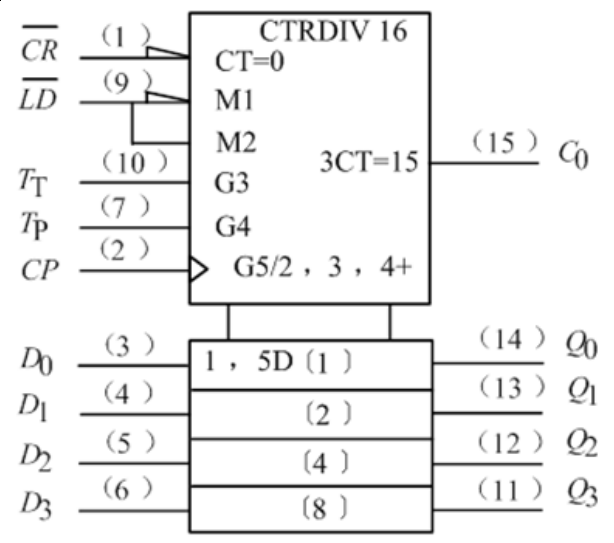

Fig. 2 Pin diagram (GB symbol) 
Counter function: Count input pulses; for timing, frequency division, etc..

Counter classification: Synchronous counter and asynchronous counter; Addition counter, subtraction counter and reversible counter; Sometimes counter counts (or modulus) of counters are used to distinguish various counters, such as binary counters, decimal counters, two - decimal counters, and so on.

Project content: 74LS161 has four functions: asynchronous clearing, synchronous setting, holding and counting.

(1) Asynchronous reset

Working conditions: When $\overline{\mathrm{CR}}=0$ (input low); The four outputs are 0 at the same time. $\times$ means that the signal can be in any form.

(2) Synchronous setting

Working conditions: $\overline{\mathrm{CR}}=1, \overline{\mathrm{LD}}=0$, and $\mathrm{CP}$ are the rising edge; results: $\mathrm{Q} 3=\mathrm{d} 3, \mathrm{Q} 2=\mathrm{d} 2, \mathrm{Q} 1=\mathrm{d} 1$, $\mathrm{Q} 0=\mathrm{d} 0$.

(3) Keep

Working conditions: $\overline{\mathrm{CR}}=1, \overline{\mathrm{LD}}=1$, and $\mathrm{T}_{\mathrm{T}} \mathrm{T}_{\mathrm{P}}=0$, that is, the two enable end is 0 ; the result is that the counter remains the same.

(4) Counting

Working conditions: $\overline{\mathrm{CR}}=1, \overline{\mathrm{LD}}=1$, TTTP $=1$, and $\mathrm{CP}$ is the rising edge; the result is that the counter performs binary addition count, and when Q3Q2Q1Q0 is 1111, the C0 becomes 1.

The functional tables of the above items are shown in table 1.

Table 1. 74LS161 function table

\begin{tabular}{|ccccccccc|cccc|}
\hline \multicolumn{1}{c|}{ Input } & \multicolumn{1}{c|}{ Output } \\
$\mathrm{CR}$ & $\mathrm{CD}$ & $\mathrm{T}_{\mathrm{T}}$ & $\mathrm{T}_{\mathrm{P}}$ & $\mathrm{CP}$ & $\mathrm{D}_{0}$ & $\mathrm{D}_{1}$ & $\mathrm{D}_{2}$ & $\mathrm{D}_{3}$ & $\mathrm{Q}_{0}$ & $\mathrm{Q}_{1}$ & $\mathrm{Q}_{2}$ & $\mathrm{Q}_{3}$ \\
\hline 0 & $\times$ & $\times$ & $\times$ & $\times$ & $\times$ & $\times$ & $\times$ & $\times$ & 0 & 0 & 0 & 0 \\
1 & 0 & $\times$ & $\times$ & $\uparrow$ & $\mathrm{d} 0$ & $\mathrm{~d} 1$ & $\mathrm{~d} 2$ & $\mathrm{~d} 3$ & $\mathrm{~d} 0$ & $\mathrm{~d} 1$ & $\mathrm{~d} 2$ & $\mathrm{~d} 3$ \\
1 & 1 & 1 & 1 & $\uparrow$ & $\times$ & $\times$ & $\times$ & $\times$ & \multicolumn{4}{c}{ Count } \\
1 & 1 & 0 & $\times$ & $\times$ & $\times$ & $\times$ & $\times$ & $\times$ & \multicolumn{4}{c}{ Keep } \\
1 & 1 & $\times$ & 0 & $\times$ & $\times$ & $\times$ & $\times$ & $\times$ & \multicolumn{4}{c}{ keep } \\
\hline
\end{tabular}

When the project is implemented, we should pay attention to the following points: First, the implementation of the project before the teacher's Guide to fine; second, according to the degree of difficulty of the project, the project group should make proper arrangements; third, the project implementation process, teachers should grasp the scale, to guide students just perfect; fourth, after the project is completed, the teacher for students to evaluate the implementation of the project summary.

\section{Summary}

Different from the traditional teaching mode, the project driven teaching model is a relatively complete work process. It pays more attention to the students' learning process, through a complete project throughout the whole knowledge point, after the students completed, according to the completion of the students to evaluate the implementation of the whole project.

\section{Acknowledgements}

This project is supported by the educational reform program of Jiangxi provincial education department in 2016. The subject number is JXJG-16-27-10. 


\section{References}

[1] Hongying Zhu, Pinhua Lai, Xiaoman Gong. Development and construction of Java curriculum and DACUM model research based on projects driven[J]. Journal of science and technology, ISTIC PKU 2014.11.

[2] Xuerong Yang, Siyuan Cheng, Zhongning Guo. Teaching reform and practice of reverse engineering technology based on the autonomous driven project[J]. Journal of the experiment technology and management, ISTIC PKU - 1, 2016.

[3] Guoyan Yu, Gui Wang, Huanlao Liu, Fenju An, Juan Zhao. Mechanical engineering exploration and practice of collaborative project teaching practice mode[J] Journal of China university teaching, PKU CSSCI 2014-12.

[4] Qin Cai, Kai Zhang. Application of project driven teaching model in the engineering teaching of software[J]. Journal of experimental science and technology, 2014.4.

[5] Li Li, Gang Chen, Xuelian Tian. Application of project drivers in the "digital signal processing" course teaching[J]. Journal of laboratory research and exploration, PKU, 2015.12.

[6] Jinfeng Li, Huanle Zhu, Wenjie Zhang. Application study of project drivers in "electronic circuit design and simulation" in classroom teaching[J]. Journal of bosom friend inspiration, 2016.04.

[7] Jinfeng Li, Wenjie Zhang. Professional quality of preparatory teachers in the classroom under the new situation[J]. Journal of hundreds prose, 2015.06.

[8] Caibing $\mathrm{Wu}$. Tungsten resource development project driving practice teaching course[M]. Metallurgical industry press, 2016.08.

[9] Yongfeng Zheng. Research on project driven curriculum system of Mechatronics major in Higher Vocational Education[D]. Zhejiang Normal University, 2014.05.

[10] Yongjun Shao. Research on comprehensive evaluation of engineering project management effect[D]. Xi'an University of Science and Technology, 2013.05. 